\title{
Hypercortisolism Signature: A Florid Case of Iatrogenic Cushing's Syndrome Induced by Topical Steroid
}

Pralhad R Rathod ${ }^{1}$, Chaitanya G Yerawar ${ }^{2}$, Sharad K Mane ${ }^{3}$ and Prerana Deokar ${ }^{4}$

${ }^{1}$ Department of Skin and VD, Shri Vasantrao Naik Government Medical College, Yavatmal, India

${ }^{2}$ Dr. Chaitanya's DTH Superspeciality Clinic, Nanded, India

${ }^{3}$ Sawedana Skin Care Hospital, Nanded, India

${ }^{4}$ Department of Biochemistry, ESI-PGIMSR, Andheri (E), Mumbai, India
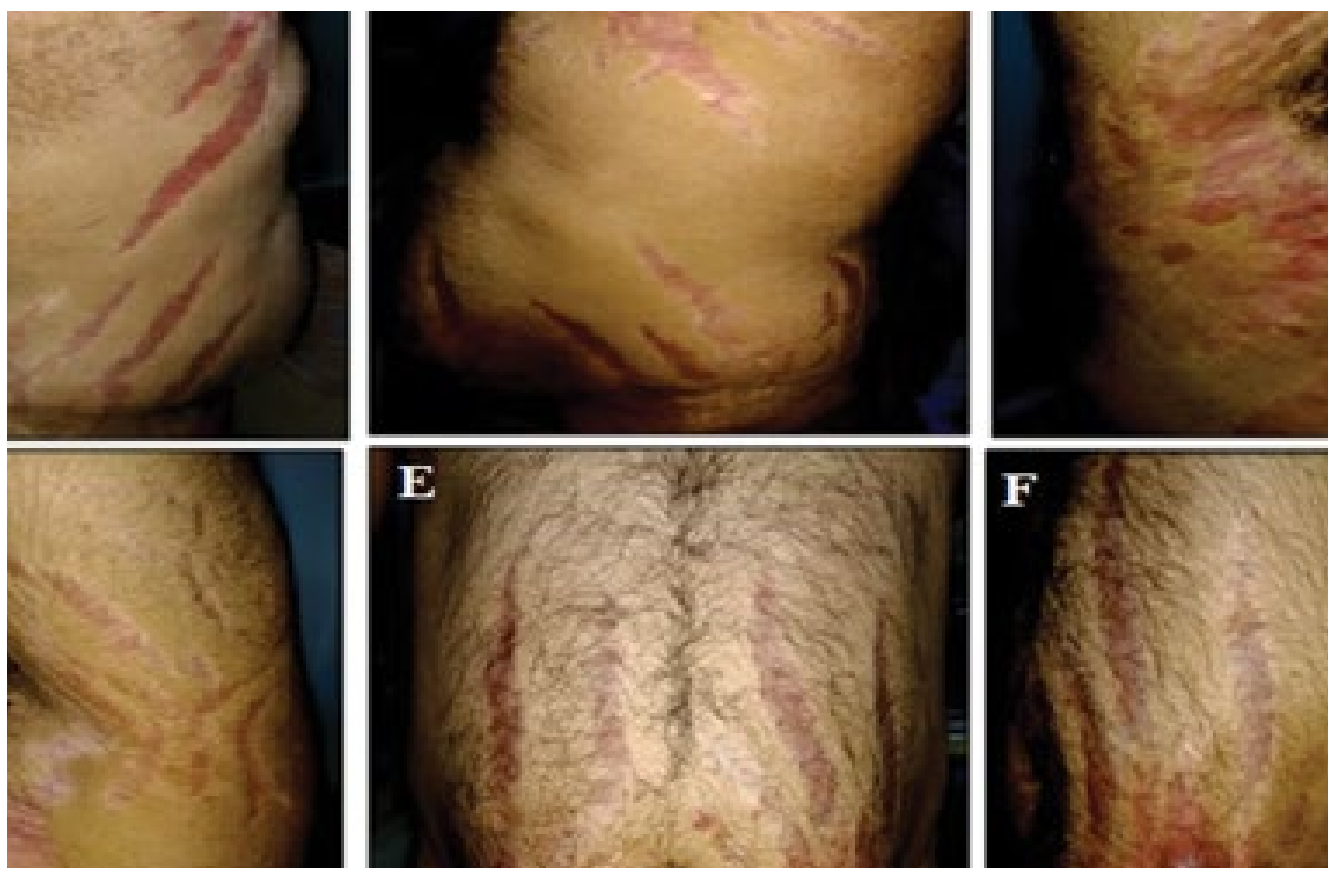

Figure 1: (A-F) Multiple broad, pink, depressed, non-tapering striae over the axilla, abdomen and thighs along with multiple boils over body.

\section{Clinical Image}

Topical corticosteroids are the most common drugs used to treat acute and chronic inflammatory skin diseases. Topical corticosteroids are available in different preparations, concentrations, and potencies. Prolonged use of them may cause systemic adverse effects including Cushing's syndrome and hypothalamic-pituitary-adrenal axis suppression. Development of the features of Cushing's syndrome depends on the dose, duration, and potency of the corticosteroids. Here we report a case of a 19-year-old young male who developed full blown iatrogenic Cushing's syndrome after use of clobetasol propionate cream $0.05 \%$ for recurrent dermatophytic infections (Tinea corporis, et cruris, et fecei) for 2-3 years. Laboratory evaluation revealed, morning (8:00 $\mathrm{AM}$ ) adrenocorticotropic hormone (ACTH): $3.2 \mathrm{pg} / \mathrm{mL}(\mathrm{N}: 0-46 \mathrm{pg} / \mathrm{mL})$; morning serum cortisol: $<0.1 \mu \mathrm{g} / \mathrm{dL}(\mathrm{N}: 5.0-25.0 \mu \mathrm{g} /$ dL) suggestive of hypothalamic-pituitary-adrenal (HPA) axis suppression secondary to topical steroid use. Other routine laboratory parameters were within normal reference range. The clobetasol propionate cream was discontinued and supplemented with oral hydrocotisone till the HPA axis recovers. This case demonstrates that injudicious prolonged use of topical steroids can have disastrous consequences (Figure 1).

*Corresponding author: Chaitanya G Yerawar, Dr. Chaitanya’s DTH Superspeciality Clinic, Nanded, India, E-mail: c_yerawar@yahoo.com

Citation: Rathod PR, Yerawar CG, Mane SK, Deokar P (2019) Hypercortisolism Signature: A Florid Case of Iatrogenic Cushing's Syndrome Induced by Topical Steroid. Int J Clin Med Imaging 6: 627. doi:10.4172/2376-0249.1000627

Copyright: (C) 2019 Rathod PR et al. This is an open-access article distributed under the terms of the Creative Commons Attribution License, which permits unrestricted use, distribution, and reproduction in any medium, provided the original author and source are credited. 